\title{
The diversity of physics revealed
}

\section{R.H. Dalitz}

Encyclopedia of Physics. Edited by Rita G. Lerner and George L. Trigg. Pp.1,157. ISBN 0-201-04313-0. (Addison-Wesley: 1981.) $\$ 99.50, £ 49.50$.

THE publication of a new encyclopaedia of physics is an important event. The subject is growing rapidly, not only in accuracy of measurement and detail of understanding but also in scope. A well organized volume can quickly bring the reader up to date about developments in areas outside his own speciality where new viewpoints and techniques may have become established, and, overall, can significantly speed up the progress of physics itself.

This volume contains about 450 entries, some long (18 pages on symbols, units and nomenclature; 11 on elementary particles) and some short (a few less than a column). They range from instrumentation (particle accelerators, photomultipliers, transistors, thermocouples and so on), through classical physics (analytical dynamics, thermodynamics, acoustics, geomagnetism etc.), to quantum physics (liquid helium, atomic spectroscopy, nuclear structure, Josephson effect and so on). The articles are all by well-known physicists. They show great diversity in both objective and style, and there is considerable overlap between them.

How well will this new encyclopaedia meet our needs? Many of the major entries are really excellent - for example those on elementary particles, liquid crystals, vision and colour, and non-equilibrium thermodynamics, to mention just several. For greatest effectiveness, each major article should really provide a substantial reference list, but not all do. That on nuclear reactions, two pages long, provides an excellent classification of work in this subject but gives only one reference, whereas other articles, such as those on electronics, the Hubble effect, and relativity (special theory), give a wide range of graded references; perhaps this is overdone for solar energy, with one and a half pages of references for a six-page entry.

With a variety of viewpoints of the contributors, the multiple coverage could be a strength, but some consolidation would have obvious advantages. To give one illustration, the entries for baryons, hadrons, hyperons, and mesons, each about a page in length, could usefully have been combined into a four page article on hadrons, the other three entries each being reduced to one line, cross-referenced to hadrons. In addition, the coverage of different topics is not always in proportion to their relative importance. For example, the rather detailed contribution on weak neutral currents is given five pages, without any corresponding counterpart for weak charged currents. Also turbulence, one of the least understood areas of physics, receives only one and a half pages.

Many of the articles read strangely for a newly published book, as if one is recalling a past time, some four or five years ago. For instance, quantum chromodynamics, our deepest and most promising theory of elementary particles, receives only one paragraph in each of the contributions on elementary particles, quantum electrodynamics, and unified field theory, despite the fact that it has provided an underlying basis for most of the theoretical work in elementary particle and high-energy physics over the past three years. The editors of an encyclopaedia face great difficulties, of course, but in this case they might have noted that a few of the articles called for some revision at the last moment.

The operational test of a reference book of this sort is whether information can be located rapidly. For this, the general index serves fairly well. I found that Higgs mechanism, radiocarbon dating, and

\section{This is psychology?}

\section{John C. Marshall}

Mindwatching. By $\mathrm{H}$. and M. Eysenck. Pp.224. ISBN 0-7181-1937-1. (Michael Joseph: 1981.) $£ 10.50$. To be published in the USA by Doubleday.

THERE's an old joke about how to select candidates for admission to psychology courses. The hapless individuals are asked the simple question "Why do you want to study psychology?" Those who reply "Because I want to understand people" are advised to read history or English literature; those who reply "Because I want to help people" are told to train as surgeons, farmers, garbage collectors or tax lawyers. Any other response secures admission to the psychology department.

Hans and Michael Eysenck would, I presume, disapprove. For them, the goal of professional psychologists is "to understand why people behave as they do, so that it will be possible to predict and change their behaviour"; this goal is to be achieved by controlled experimentation, the results of which are sometimes counterintuitive and thus undermine the sceptic's claim that my grandmother knew as much " "psychology" as it is possible (or wise) for any mere mortal to comprehend. The Eysencks have accordingly produced this coffee-table volume in which the purported achievements, theoretical and practical, of experimental psychology are laid out for interested bystanders. Two questions therefore arise: First, to what extent are we presented with a fair summary of modern psychology? Second, are the social implications of current work outlined in a
Peierls stress were in the index, as was Umklapp process, although with reference to p.732 where only articles on partial waves and partons are to be found. There is no entry for current algebra but the article on currents in particle theory is indexed nearby and led me to my goal. However there is no entry for Thomas precession, nor for photon multiplier, nor even for the Wigner-Eisenbud theory of the R-matrix and its application to resonance processes.

This encyclopaedia has a great deal to offer to scientists and engineers in general, as well as physicists. The underlying plan is sound and the articles generally authoritative. With so many first-rate contributions, it should have an assured place in all science libraries. It could be substantially improved, in my opinion, but, as things stand, it is the best compilation of its type available for physics today.

R. H. Dalitz is Royal Society Research Professor in Theoretical Physics at Oxford University.

\section{responsible fashion?}

The authors employ the stylistic device of describing in each chapter a so-called " $k$ ey experiment", supplemented by anecdote and speculation. This is not in itself a bad strategy but it does lead the Eysencks into letting vaudeville prevail over rationality. For example, a section on "Attractiveness and jury decision-making" is introduced by the story of a famous nineteenthcentury trial in which a woman accused of poisoning her lover was somewhat lucky to obtain a verdict of "not proven". The Eysencks speculate that since the defendant was "young, vivacious, and beautiful", these attributes may have influenced the jury and "helped to save her from the gallows". An experiment is then described in which mock juries who consider hypothetical cases of a relatively minor nature do indeed seem to be swayed a little by the physical attractiveness of the mock defendants. But the section then concludes with the claim that "most of the available research suggests that physical attractiveness has little or no effect on juries when serious crimes are involved"'. I can only make sense of this information by assuming the Eysencks believe that murdering one's lover is not a serious crime.

On other occasions the authors are unable to resist the temptation of a spectacular but fatally flawed study. They thus feature Rosenham's report in which a group of normal people were admitted to mental hospitals after falsely complaining that they heard voices and asking to be admitted. Following an average stay of 19 
days the pseudo-patients were discharged with a diagnosis of "schizophrenia in remission". On the basis of this and a number of related pranks, Rosenham concluded that "It is clear that we cannot distinguish the sane from the insane in psychiatric hospitals". Very amusing, no doubt, but normal people who are not in the pay of psychologists either don't hear The Eysencks themselves quote Seymour Kety's withering comment - " "If I were to drink a quart of blood and, concealing what I had done, come to the emergency room of any hospital vomiting blood, the behaviour of the staff would be quite prehaving a bleeding peptic ulcer, I doubt that I could argue convincingly that medical science does not know how to diagnose that condition" - but they are not thereby inhibited from describing Rosenham's jest as a "key experiment".

Not all of the selections are as silly as Rosenham's study. The book contains quite sensible sections on eye-witness testimony, divided attention and forto teach sign language to chimpanzees is an improvement on many popular treatments of the topic. But these islands of sanity are lost in the surrounding sludge of trivia and titillation. What can one say of a book which proclaims that psychology should "be regarded as the most important of all the sciences" and then reports that "Small breasts were preferred by men with fundamentalist religious beliefs suffering from mild depression"'? voices or, if they do, are not sufficiently worried by it to seek admission to hospital. dictable. If they labelled and treated me as getting. Similarly, the chapter on attempts

There is little improvement when the Eysencks draw out the practical implications of their choice of topics. We are informed that a process of conditioning can turn our children into "wellintegrated, honest members of society" and referred to Chapter 6 for the experimental evidence that this is so. Chapter 6, however, reports that obsessive and compulsive disorders can be treated by "behaviour therapy". In Chapter 22, a discussion of Hans Eysenck's "theory" of personality is held to support the claim that "The egalitarian principle underlying socialism is in conflict with biological reality and can only be enforced by dictatorship". Exactly how this conclusion is reached remains shrouded in mystery. An appallingly ill-controlled "experiment" on the effects of two types of play-group prefaces the remark that "the advocates of progressive teaching. . have turned our pre-school groups, kindergartens and primary schools into permissive places of no work and all play, from which all socializing and restraining influences have been banned".

One can only hope that this grubby little opus will sink without trace. It totally fails to represent those aspects of psychology where results of some intellectual depth have been obtained in the study of perception, language and skilled action; it similarly ignores many areas of occupational, clinical and educational research where careful, thoughtful work has served to enhance the quality of life.

John C. Marshall is in the Neuropsychology Unit, part of the Neuroscience Group at the Radctiffe Infirmary, Oxford.

\section{Find the (North American) bird}

\section{Clayton M. White}

The Audubon Society Encyclopedia of North American Birds. By John K. Terres. Pp.1,109. ISBN 0-3944-6651-9. (Knopf: 1980.) \$60 US only.

IN 1896 Professor Alfred Newton published his Dictionary of Birds. Thus a mould was cast. But it took another 68 years, until 1964, through the British Ornithologists' Union and under the editorship of A. Landsborough Thomson, for another such work to appear: $A \mathrm{New}$ Dictionary of Birds. Now, only 16 years later, another giant encyclopaedia is on the market. To me, this current volume appears to be an attempt to update a considerable body of material from the now elusive New Dictionary. Its scope, however, is mainly restricted to North America.

The book is designed to be a singlevolume work for both layman and professional, but I suspect the lay will benefit most. There are nearly 6,000 alphabetically arranged entries and cross references, illustrated with 875 full-colour photographs of bird species and over 800 black-and-white drawings. The scope of the entries is impressive: Birdhouse, Bird Lice, Birds as Collectors, Birds as Watchdogs, Bird Skin, Bird-Watcher, Bisexuality, Bittern, Blackburne, among the "B's" for example. Abbreviated life histories of 847 birds are provided. For each species are given a description of the Latin or Greek origin of the scientific name (a most valuable feature), the bird's geographical range, colour and distinctive morphological features, habitat, feeding habits, other names, nest, eggs, and other features of interest (such as who parasitizes whom). Terres cites over 4,000 references, ranging in date from the turn of the $1800 \mathrm{~s}$ to 1980 , all of which are listed in a bibliography. The bulk of several alphabetical sections is taken up by species accounts. The taxonomic treatment is fairly current by both European and American standards, at least in common names, but is more conservative and departs somewhat from the nomenclature of Peter's
Check-list of Birds of the World. For example, Terres leaves the titmouse family intact and includes the long-tailed tits (Aegithalinae) and penduline tits (Remizinae) as subfamilies rather than treating them as distinct families as has been recently practised. On the other hand, the thrushes are retained in their own family, Turdidae, and there is no mention of their current placement as a subfamily in the Old World flycatcher family, Muscicapidae.

While the book has many virtues it falls short of the stated goal of providing information on all the birds that have nested or been sighted in Alaska, Canada, Greenland, Bermuda, Baja California and the 48 contiguous states of the USA. Omissions are conspicuous, for example, in the Alaskan avifauna. While the 1978 update of the status of Alaskan birds is referenced in numerous places, and 1980 Alaskan references are also given, it is annoying that no less than 22 Alaskan species given in the 1978 publication are ignored. For instance, while the willow warbler (an Old World warbler) is discussed, nothing is said about its North American status. Only its Eurasian distribution is mentioned, so readers are not aware that it has occurred as an accidental in Alaska.

Another flaw is that the book's attractiveness is compromised by lumping colour plates together in sections. For example, located in the middle of the thrush family species accounts are 31 pages of colour plates of tanagers, thrush family, titmouse family, trogon, tropicbirds, troupial (American blackbird) family, turkey, vireo family and New World vultures and condors - rather a potpourri even though they are in alphabetical order. As with most undertakings of this magnitude other errors, mainly of editorial style, creep in. Under "Fecal Sac" we are referred to "Nests and Nestlings" but there is nothing on the sac there. A second reference under "Fecal Sac" is "Nest Sanitation"' which is there, but under that title we are referred further to "Young and Their Care" which contains a discussion of nest sanitation and fecal sacs. Further minor inconsistencies are the listing of "Courtship" with sub-topics such as courtship rituals but not courtship feeding. This latter appears as a completely separate topic followed by "Courtship Flight", which then only refers the reader back again to "Courtship" and "Flight".

Despite my less-than-total enthusiasm with the Encyclopedia, on balance Terres has done a remarkable job in producing a scientifically accurate tome relatively free of typographical errors. With over 7 million bird-watchers in the US alone (as of 1970), of which at least 3 million were considered to be seriously interested in field ornithology, there should be a receptive audience to savour this book.

Clayton M. White is a Professor of Zoology at Brigham Young University, Provo, Utah. 